\title{
Silene as a model system in ecology and evolution
}

\author{
G Bernasconi ${ }^{1,2}$, J Antonovics ${ }^{3}$, A Biere ${ }^{4}$, D Charlesworth ${ }^{5}$, LF Delph ${ }^{6}$, D Filatov ${ }^{7}$, T Giraud ${ }^{8}$, ME Hood ${ }^{9}$, \\ GAB Marais ${ }^{10}$, D McCauley ${ }^{11}$, JR Pannell ${ }^{7}$, JA Shykoff ${ }^{8}$, B Vyskot ${ }^{12}$, LM Wolfe ${ }^{13}$ and A Widmer ${ }^{14}$ \\ ${ }^{1}$ Institute of Biology, University of Neuchâtel, Neuchâtel, Switzerland; ${ }^{2}$ Department of Ecology and Evolution, University of Lausanne, \\ Lausanne, Switzerland; ${ }^{3}$ Department of Biology, University of Virginia, Charlottesville, VA, USA; ${ }^{4}$ Department of Multitrophic \\ Interactions, Netherlands Institute of Ecology NIOO-KNAW, Heteren, The Netherlands; ${ }^{5}$ Institute of Evolutionary Biology, School of \\ Biological Sciences, University of Edinburgh, Edinburgh, UK; ${ }^{6}$ Department of Biology, Indiana University, Bloomington, IN, USA; \\ ${ }^{7}$ Department of Plant Sciences, University of Oxford, Oxford, UK; ${ }^{8}$ Ecology, Systematique et Evolution, CNRS-Université Paris-Sud XI, \\ Orsay, Cedex, France; ${ }^{9}$ Department of Biology, Amherst College, Amherst, MA, USA; ${ }^{10}$ Laboratoire de Biométrie et Biologie évolutive, \\ Centre National de la Recherche Scientifique, Université de Lyon, Université Lyon 1, UMR5558, Villeurbanne, Cedex, France; \\ ${ }^{11}$ Department of Biological Sciences, Vanderbilt University, Nashville, TN, USA; ${ }^{12}$ Department of Plant Developmental Genetics, \\ Institute of Biophysics, Academy of Sciences of the Czech Republic, Brno, Czech Republic; ${ }^{13}$ Department of Biology, Georgia Southern \\ University, Statesboro, GA, USA and ${ }^{14} E T H$ Zurich, Institute of Integrative Biology, Zürich, Switzerland
}

\begin{abstract}
The genus Silene, studied by Darwin, Mendel and other early scientists, is re-emerging as a system for studying interrelated questions in ecology, evolution and developmental biology. These questions include sex chromosome evolution, epigenetic control of sex expression, genomic conflict and speciation. Its well-studied interactions with the pathogen Microbotryum has made Silene a model for the evolution and dynamics of disease in natural systems, and its interactions with herbivores have
\end{abstract}

increased our understanding of multi-trophic ecological processes and the evolution of invasiveness. Molecular tools are now providing new approaches to many of these classical yet unresolved problems, and new progress is being made through combining phylogenetic, genomic and molecular evolutionary studies with ecological and phenotypic data.

Heredity (2009) 103, 5-14; doi:10.1038/hdy.2009.34;

published online 15 April 2009

Keywords: sex chromosome evolution; speciation; sexual conflict; biological invasions; Microbotryum; Hadena

\section{The model role of a non-model organism}

The genus Silene (Caryophyllaceae), with a tradition of genetical and ecological studies dating back to Mendel and Darwin, has remarkably many interesting features. First, the species in the genus vary widely in their breeding systems and ecology. Second, several members of this mainly holarctic genus can be easily bred, and have short life cycles, and are thus convenient for experimental and field studies. Genomic resources are now becoming increasingly available in Silene, making genetic, quantitative genetic and molecular studies possible. A strength of Silene as a model system, compared with many classical model organisms, is that researchers can rely on a large number of ecological studies encompassing biotic interactions with sexually transmitted fungi, pollinators and herbivores. It is the wealth of ecological and other earlier knowledge that makes the genus Silene important for studying many biological questions, including the suppression of recombination during sex chromosome evolution, sexually antagonistic selection in an organism that is not an animal, epigenetic processes in flower development, speciation and reproductive isolation, multi-trophic interactions, disease ecology and biological invasions.

Correspondence: Professor G Bernasconi, Institute of Biology, University of Neuchatel, Rue Emile Argand 11, Neuchatel 2009, Switzerland.

E-mail: giorgina.bernasconi@unine.ch

Received 15 November 2008; revised 26 January 2009; accepted 29 January 2009; published online 15 April 2009
Thanks to the classical genetic and ecological work on Silene, new progress can now be made in studying some of these important unresolved questions in biology with the aid of modern molecular tools. That new model systems with accessible and well-studied ecology open fruitful avenues for investigation is illustrated also by Mimulus (Wu et al., 2008) and the ongoing efforts to develop genomic resources in an increasing number of different systems. In the following, we outline the unique features of the Silene system, and describe active research areas and future directions, highlighting new advances and work in progress.

\section{Evolution of sexual systems}

Plants show remarkable diversity in their sexual and mating systems, ranging from hermaphroditism to dioecy, from self-incompatible hermaphroditism to hermaphroditism in which individuals possess a capacity to self-fertilize, but which often show complex mechanisms to promote outcrossing (Darwin, 1877; Barrett, 2002). Understanding the origin and maintenance of this diversity has been a central goal of plant evolutionary biology, and much can be learned from studies that compare closely related species or populations that vary in their sexual system. The genus Silene was recognized since the early days of evolutionary biology as important for studying sexual and mating systems. The genus includes members that are self-fertile hermaphrodites, some of which are cleistogamous, self-incompatible hermaphrodites, but also sexually polymorphic species 
expressing dioecy (separate sexes) and unusual systems such as gynodioecy (polymorphism for females and hermaphrodites) (Darwin, 1876, 1877; Barrett, 2002). Indeed Silene (then Lychnis) was used by Darwin to illustrate dioecy as a state derived from ancestral hermaphroditism (Darwin, 1876, pp 410-411) and Silene has continued to be central in studies of sexual and mating system evolution (Baker, 1963) and more recently even evolution of sex determination systems because some of the dioecious species of this genus have even evolved heteromorphic sex chromosomes (see below).

DNA sequence data allow reliable phylogenetic reconstructions in many taxa of biological interest, including Silene (Oxelman et al., 1997). These reveal that dioecy evolved independently at least twice in the genus (Desfeux et al., 1996). In the clade that includes Silene latifolia, sex chromosome heteromorphism has also evolved (see below, (Armstrong and Filatov, 2008); Figure 1), whereas in another dioecious clade, Silene colpophylla has no heteromorphic sex chromosomes, and genes that are sex-linked in S. latifolia are not linked to the $S$. colpophylla sex-determining locus (Mrackova et al., 2008). Dioecy probably evolved through gynodioecy (Maurice et al., 1993; Schultz, 1994), therefore the common occurrence of gynodioecy in the genus Silene has long been of interest. Nucleo-cytoplasmic inheritance of male sterility (interaction between cytoplasmic male sterility (CMS) factors and nuclear restorers of fertility) was established by classical genetic work (see below), and theoretical work has shown how intra-genomic conflict between maternally and biparentally inherited genes can lead to the maintenance of such gender polymorphism. In some Silene species, male-sterile individuals are rare, and some females produce perfect hermaphrodite flowers (Desfeux et al., 1996). In other species, females are very common (Shykoff, 1988; Delph and Mutikainen, 2003).

In theory, nucleo-cytoplasmic gynodioecy might sometimes lead to the evolution of separate sexes (Maurice et al., 1993; Schultz, 1994). Empirical tests may, in the future, be possible in Silene. It is not yet clear whether, or how, quantitative variation in sex functions relates to the evolution of fully separate sexes, but Silene species are excellent for quantitative genetic studies, having a fairly rapid life cycle and relatively small adult size. Current topics of quantitative genetic studies in Silene are mainly focussing on the evolution of sexual dimorphism and sexually antagonistic selection (see below). Also in this context, it is particularly the dioecious Silene that provide a test case for comparing shared/parallel evolutionary processes in plant and animal systems.

\section{Sex chromosome evolution}

The existence of species with sex chromosomes within the broad variation of sexual systems found within the genus allows comparison with other well-studied sex chromosomes (for example, those of mammals) for investigating the generality of processes acting during sex chromosome evolution. Sequence and genetic mapping data have shown that the sex chromosomes in $S$. latifolia and $S$. dioica evolved recently from a pair of autosomes (Filatov, 2005a). Divergence between the sequences of homologous genes on the $\mathrm{X}$ and $\mathrm{Y}$ chromosomes indicates an age of $<10$ million years (Filatov, 2005a), yet marked chromosome heteromorphism has already evolved, with remarkable similarity to the human XY pair. In mammals, the $X$ chromosome carries over one thousand genes and is mostly euchromatic, whereas the $\mathrm{Y}$ chromosome has few functional genes and is mostly heterochromatic. The sex chromosomes pair during male meiosis, but undergo genetic recombination only in small pseudoautosomal regions. Gene loss from the $Y$ chromosome ('genetic degeneration') accompanied suppression of recombination in different regions of the mammalian and bird XY chromosome pairs, creating 'evolutionary strata'. The oldest stratum includes highly diverged genes that ceased recombining long ago, whereas genes in the youngest stratum are much less diverged (Lahn and Page, 1999). Over the last decade, several S. latifolia sex-linked genes have been identified (for example, Matsunaga et al., 2003; Filatov, 2005b), and they reveal that Silene sex chromosomes also have evolutionary strata with different divergence levels, indicating that recombination between these chromosomes also stopped in a step-wise manner over time (Nicolas et al., 2005; Bergero et al., 2007).

The recently evolved $\mathrm{Y}$ chromosome of $S$. latifolia is more suitable than the ancient, highly degenerated, human Y chromosome for studying the evolutionary processes causing the loss of functional genes from the $Y$ chromosome. S. latifolia $\mathrm{Y}$ genes show signs of degeneration,
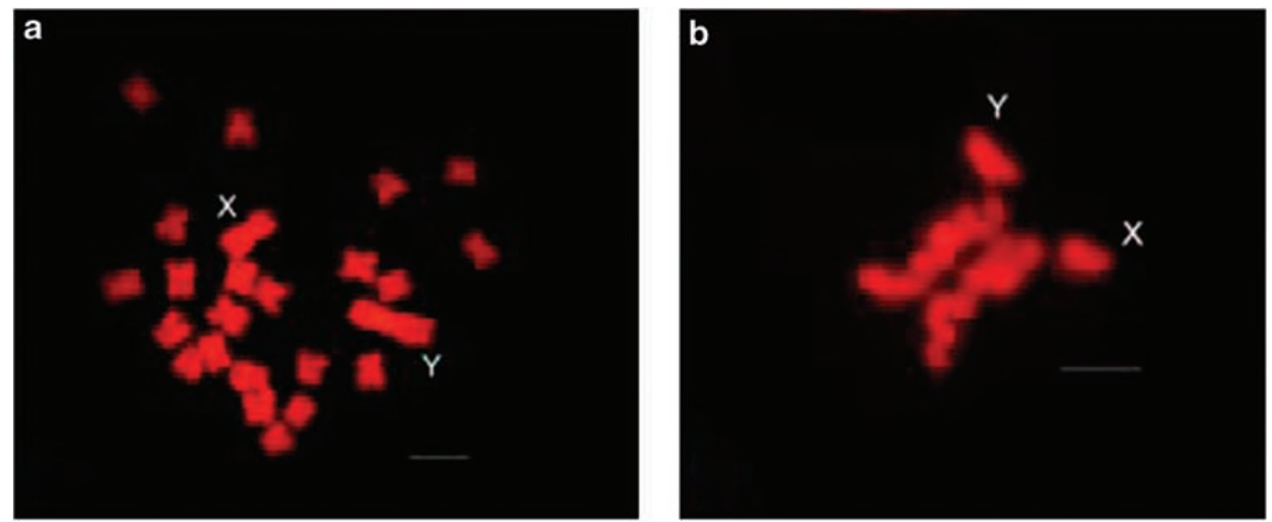

Figure 1 (a) Male mitosis prepared from germinating Silene latifolia seeds. (b) Meiotic metaphase I in pollen mother cells of Silene latifolia. Although the autosomes are still pairing, a precocious separation of the $\mathrm{X}$ and $\mathrm{Y}$ chromosomes begins. Chromosomes are counterstained with 4',6-diamidino-2-phenylindole (DAPI); the sex chromosomes ( $\mathrm{X}$ and $\mathrm{Y}$ ) are indicated. Scale bar: $10 \mu \mathrm{m}$ (B. Vyskot). 
including fast protein evolution, mutations damaging sites known to be important for protein activity (Filatov, 2005c), low expression level and insertions of transposable elements in introns (Marais et al., 2008) and severely reduced polymorphism, an indirect effect of the processes that cause degeneration (Filatov et al., 2000). Cytogenetic analysis of $S$. latifolia chromosomes shows accumulation of repeat sequences on the $Y$ chromosome (Kubat et al., 2007).

The numbers of genes on the Silene sex chromosomes are still unknown, but probably greatly exceed the 10 currently known sex-linked genes. The S. latifolia genome is very large (its DNA content is similar to that of the human genome), consistent with a high repetitive content throughout the genome (Cermak et al., 2008). Sequencing and assembling this genome is currently infeasible, but partial sequencing is possible using BAC libraries, and comparative analysis of genomic DNA sequences from the $\mathrm{X}$ and $\mathrm{Y}$ chromosomes can potentially provide estimates of gene loss from the $Y$ chromosome.

Expressed sequence tag databases are also being developed, and will provide genetic markers for mapping the sex chromosomes, for fluorescent in situ hybridization (Armstrong and Filatov, 2008) and for comparing expression differences between X- and Ylinked alleles (Marais et al., 2008). Expression studies may also help to identify sex-determining genes in $S$. latifolia, about which we still know very little, despite having some knowledge of the pathways involved in the floral developmental programs in Silene (Zluvova et al., 2007) and the $Y$ chromosomal regions involved in maledetermination (Lardon et al., 1999; Lebel-Hardenack et al., 2002; Bergero et al., 2008).

The young age of the Silene sex chromosomes may provide insights into another very interesting set of questions concerning how and why $X-Y$ recombination is suppressed. As in mammals, recombination between the Silene $\mathrm{X}$ and $\mathrm{Y}$ chromosomes is restricted to small 'pseudoautosomal' regions (Figure 2). A plausible hypothesis for the evolution of the non-recombining regions is that, as sex chromosomes evolve, sexually antagonistic genes (enhancing male fertility, but with negative effects in females) accumulate, particularly on $Y$ chromosomes (see also below, 'sexual dimorphism and sexual antagonism'). Polymorphism for sexually antagonistic alleles, maintained by such conflicts, creates selection against recombination (which would move such alleles onto the X). A young sex chromosome system in which genetic mapping is possible offers opportunities for testing for such genetic variants, which have not yet been identified in any organism; studies in Silene have a promise for finding such genes. Mammalian $\mathrm{Y}$ chromosomes are rearranged, and do not permit inferences about whether non-recombining regions evolved through inversions suppressing recombination, but data in Silene are suggesting that inversions alone are not responsible (Zluvova et al., 2005; Bergero et al., 2008).

\section{Reproductive isolation and species boundaries}

Studies on animals have established that sex chromosomes play a major role in the evolution of reproductive isolation between species, but little is known about

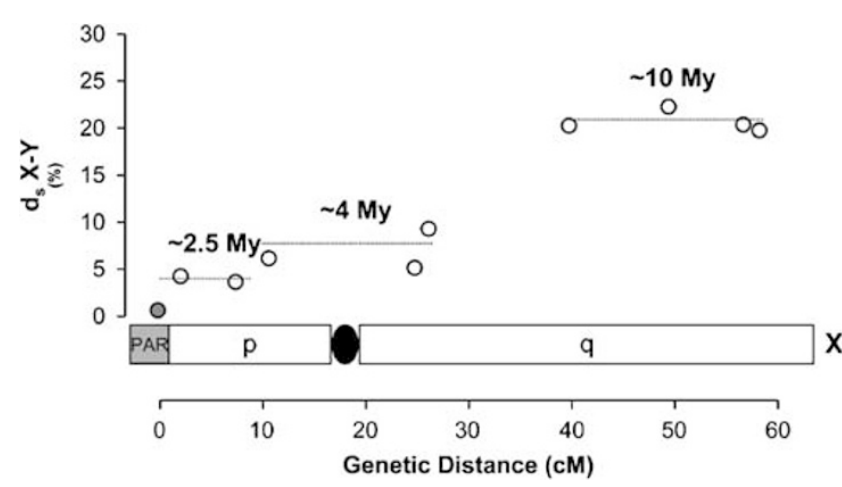

Figure 2 Evolutionary strata in Silene latifolia. The synonymous divergence between $X$ and $Y$ copies ( $y$ axis, $\% d_{s} X-Y$ ) and the position of the $X$ copy of the $X$ chromosome genetic map ( $x$ axis) are shown for the 10 known sex-linked gene pairs (circles). This plot shows that at least three events of recombination suppression between $\mathrm{X}$ and $\mathrm{Y}$ have occurred in S. latifolia. The dates of these events calculated assuming molecular clock $\left(1.8 \times 10^{-8}\right.$ syn. substitutions/syn. site/year) are shown. Adapted from Nicolas et al. (2005) and Bergero et al. (2007).

plants, and Silene is ideal for investigating this. In animals, 'two rules of speciation' have been stated in relation to postzygotic reproductive isolation (Coyne and Orr, 1989). 'Haldane's rule' summarizes the observation that, in crosses between species with chromosomal sex determination, when one sex is absent, rare or sterile, it is usually the heterogametic sex. 'The large X-effect' is the frequently large role of the $X$ chromosome in hybrid sterility (Coyne and Orr, 1989).

As sex chromosomes evolved recently in Silene, we may be able to discover genomic regions associated with reproductive isolation in related species pairs with sex chromosomes. This will allow direct tests of whether genes and coevolved gene complexes involved in reproductive isolation have accumulated on the sex chromosomes.

Recombination is suppressed across most of the Silene $Y$ chromosome and the $X$ chromosome recombines only in females. Recombination thus cannot disrupt coadapted gene complexes on the $\mathrm{Y}$ chromosome and is less likely to do so on the $X$ chromosome compared with the autosomes. Gene introgression after hybridization between cross-compatible species is thus predicted to be lower for the $\mathrm{Y}$ chromosome than the $\mathrm{X}$ chromosome (and should be highest for the autosomes). Indeed, isolation between $S$. latifolia and $S$. dioica (assessed by $F_{\mathrm{ST}}$ for DNA sequence variants in two genes), is significantly stronger on the non-recombining $\mathrm{Y}$ chromosome, compared with the recombining $X$ chromosome, even taking into account the lower within-population variability of $Y$ than $X$ sequences (Ironside and Filatov, 2005).

Sex chromosomes are not the only genetic factors in Silene that may link sex determination and reproductive isolation. Gynodioecy, the coexistence of hermaphrodite and female individuals, is probably ancestral in the genus (Desfeux et al., 1996) and is typically controlled by interactions between mitochondrial CMS factors and nuclear fertility restorers. CMS factors can also influence compatibility between species through the loss of coordination between nuclear and organellar genes inherited from different parents (Chase, 2007). The species-rich genus Silene provides an excellent system 
for assessing the contribution of nuclear-cytoplasmic interactions to reproductive isolation between species.

\section{Epigenetic processes}

The existence of sex chromosomes also raises questions about dosage compensation of X-linked genes for maintaining correct gene expression levels in XY-male plants and suppression of pistil development in flowers of male plants. The role of epigenetic processes in the control of gene and sex expression is thus also being studied in the dioecious S. latifolia.

If the S. latifolia Y chromosome is genetically degenerated, gene dosage may be compensated, either by silencing of one $X$ chromosome copy in females (as in mammals) or by increasing the activity of the single $X$ chromosome copy in males (as in Drosophila). Cytogenetic experiments indicate reproducible changes in chromatin structure of the S. latifolia sex chromosomes (Vyskot et al., 1993), including DNA replication timing differences and methylation differences between the two $X$ chromosomes in female somatic cells, reminiscent of the mammalian dosage compensation mechanism (lyonisation), which also involves DNA methylation (Figure 3). With the availability of sex-linked S. latifolia genes, it becomes possible to test whether dosage compensation has also evolved in dioecious plants.

Epigenetic processes represent mechanisms by which gene expression can be reversibly suppressed. In large plant nuclear genomes, such as $S$. latifolia $(2 \mathrm{C} \sim 5.8 \mathrm{pg}$ DNA), up to $30 \%$ of all cytosine residues are methylated, both in $\mathrm{CpG}$ doublets and in $\mathrm{CpNpG}$ triplets. A simple treatment of plant meristems with a cytosine analog, 5-azacytidine, can dramatically reduce the nuclear genome 5-methylcytosine content. It is surprising that the only phenotypic change observed with this treatment in male $S$. latifolia was sex reversal, manifested as frequent bisexuality of flowers in karyotypically male (XY) individuals (Figure 4) (Janousek et al., 1996). The inflorescences of these plants are mosaics of staminate and perfect flowers, consistent with epigenetic control (Vyskot, 1999). The effect is heritable, and the 'epimutation' involved showed Y-linked inheritance in reciprocal crosses with wild-type plants. 5-azacytidine blocks DNA methylation, and generally activates genes. In this case, however, it inactivates a Y-linked female suppressor function, perhaps through DNA overall hypomethylation-induced silencing. Frequent sex reversal from male to hermaphroditism was also observed when apical meristems were treated with trichostatin A, an inhibitor of histone deacetylase (Negrutiu et al., 2001), supporting the possibility of epigenetic control of sexual development in the dioecious S. latifolia.

\section{Sexual dimorphism and sexual antagonism}

Yet another consequence of having separate sexes in several Silene species is sexual dimorphism (phenotypic differences between males and females), which is widespread in gonochoristic animals and dioecious plants (Geber et al., 1999). Its occurrence suggests that selection acts on traits in a sex-specific manner. However,
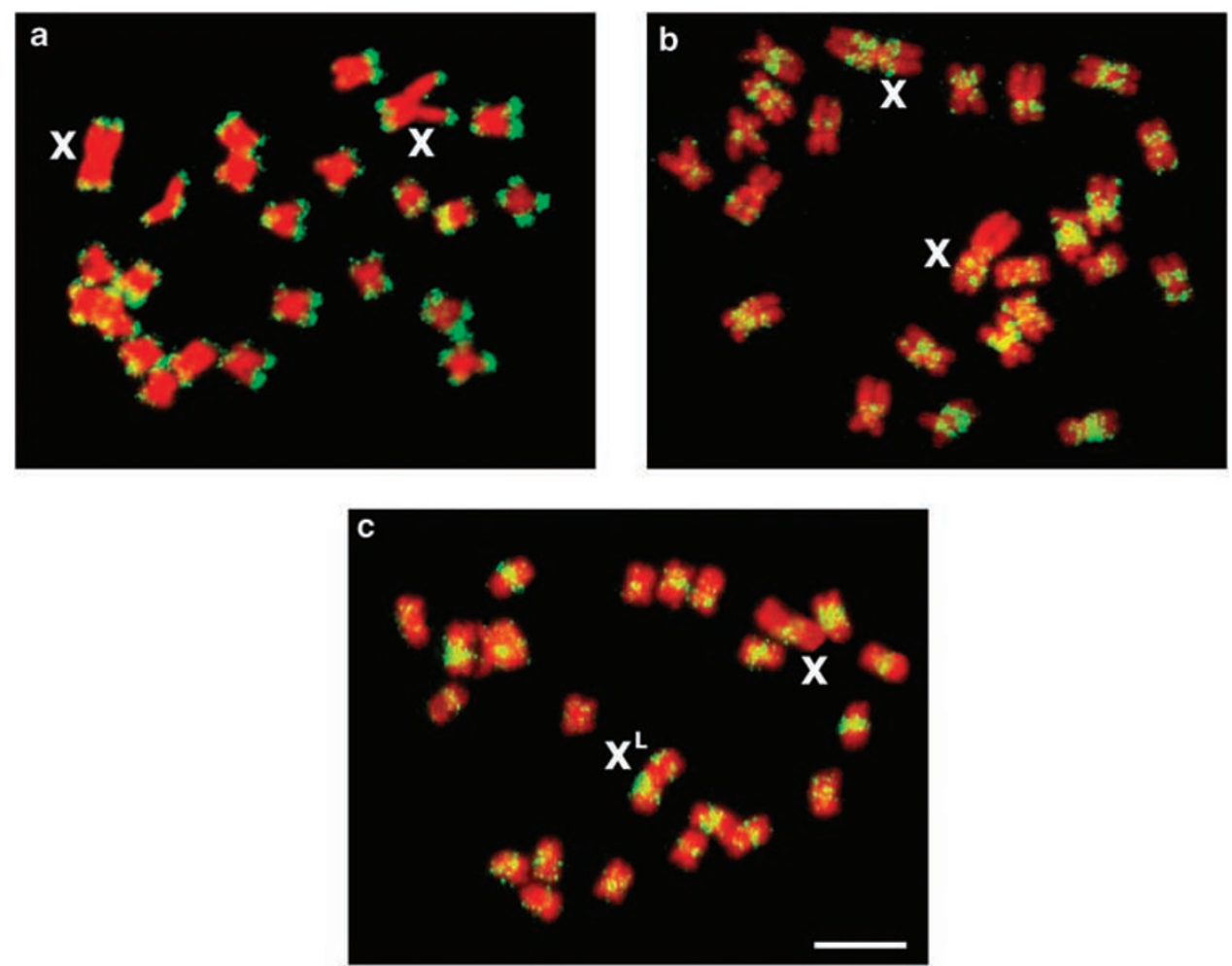

Figure 3 DNA replication patterns of female mitotic metaphases of S. latifolia after 5-bromo-2'-deoxyuridine (BrdU) labeling and FITCimmunodetection (green). (a) Early pulse of BrdU shows that the chromosomes start to replicate at their ends. (b) BrdU applied at the middle of S phase. (c) Metaphase of the cell labeled at late period of the $S$ phase showing largely only centromeric signals, but one $X$ chromosome is late replicating $\left(\mathrm{X}^{\mathrm{L}}\right)$. Chromosomes are counterstained with 4'-6-diamidino-2-phenylindole (DAPI) (red); $X$ chromosomes are indicated. Scale bar: $10 \mu \mathrm{m}$ (B. Vyskot). 

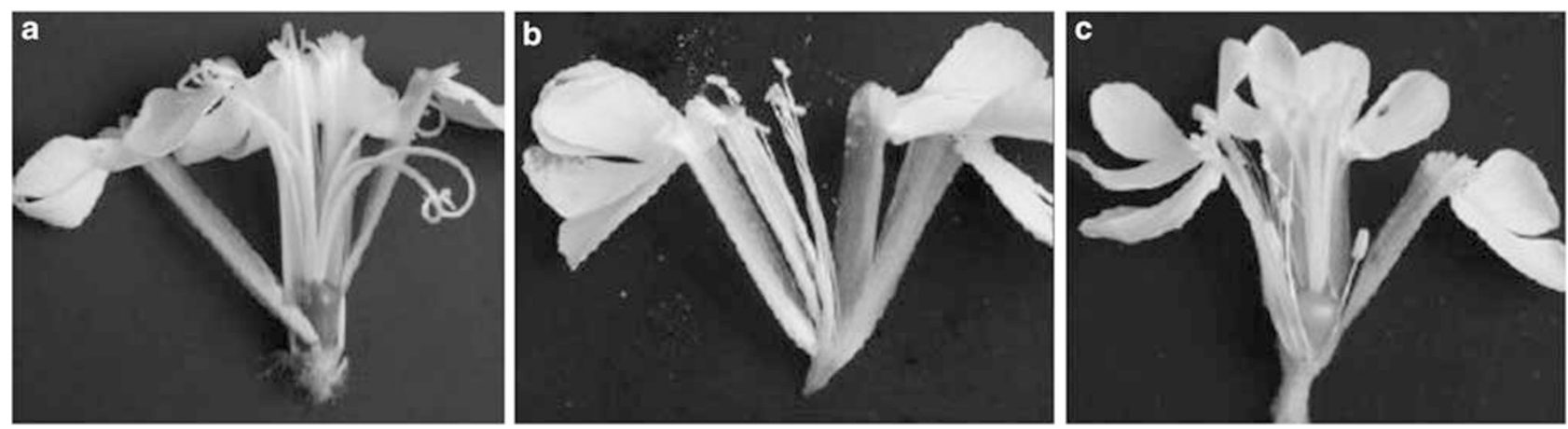

Figure 4 Flower sexual phenotypes of the dioecious S. latifolia. Calyx of the flowers was removed to display sexual organs. (a) Standard pistillate flower from a female (karyotype XX) flower showing only gynoecium formation: the ovary with five styli. (b) Standard staminate flower from a male (karyotype XY) flower with ten stamens. (c) Hermaphrodite flower from a male (karyotype XY) with both gynoecium and staminate formation obtained after 5-azacytidine treatment on germinating seeds (B. Vyskot).

homologous genes that are expressed in both sexes lead to overall positive genetic correlations between the sexes, and this can prevent the evolution of sexual dimorphism and lead to sexually antagonistic gene expression (Bedhomme and Chippindale, 2007).

Dioecious Silene species are excellent for studying this phenomenon. As dioecy has arisen more than once within Silene, there are opportunities for comparative studies to test hypotheses about its evolution. Although dioecy is not rare among flowering plants, many dioecious species are woody, long-lived trees (Renner and Ricklefs, 1995), which makes genetic studies difficult, even in crop species. In contrast, several dioecious Silene species are short-lived perennials that often flower in their first year, allowing experiments to be done within a short time frame. Moreover, it gives the opportunity for comparing many life-history traits between the sexes, including longevity.

Good measures of sexual dimorphism for a variety of traits, together with the underlying genetic variation and covariation within and between the sexes, can be obtained by established quantitative-genetic crossing designs or artificial-selection experiments. Such experiments have shown remarkable sexual dimorphism and genetic correlations between the sexes for multiple fitness-related traits in S. latifolia (Meagher, 1999; Delph, 2007). Flower size, flower number and leaf traits have been extensively studied; these traits vary in their means and degree of sexual dimorphism among populations, and genetic correlations within and between the sexes are high (Steven et al., 2007). Sex-specific quantitative trait loci have been found for these traits, especially in males; the finding that the major ones are on the sex chromosomes (Scotti and Delph, 2006) suggests that the studies on the evolution of sexual dimorphism in this species may uncover examples of sexual antagonism.

Correlations between traits within the sexes can also constrain the evolution of sexual dimorphism. In Silene (and plants more generally), ecologists can often use proxies for the fitness of individuals in experimental and/or natural settings, such as flower and fruit production, and relate this to variation in traits of interest, such as sexually dimorphic traits. Phenotypicselection experiments in populations that differ in their degree of sexual dimorphism have revealed the extent to which correlations between traits within the sexes constrain the evolution of sexual dimorphism. Another way to study how trait variation affects fitness is to plant experimental arrays of individuals with extreme phenotypes and with known genetic markers, and test the different phenotypes' performance over time. Given the important interspecific interactions between various dioecious Silene species and their pollinators/seed predators and pathogens, it will be interesting to see how the various players contribute to the existence of sexual antagonism.

\section{Organelle DNA}

Organelle DNA is known to play a role in sex determination in Silene and the properties of the chloroplast and mitochondrial genomes of several Silene species have recently received considerable attention. Interest in the mitochondrial genome traces largely to the cytonuclear sex determination in gynodioecious Silene. Cytonuclear gynodioecious systems are a prime example of genetic conflict. When the inheritance of CMS elements is maternal (as is usually assumed for mitochondrial genes), evolutionary conflicts occur between the fitness interests of the mitochondrial genome (more and/or better seeds produced by females enhances mitochondrial fitness) and those of the nuclear genome (higher transmission of genes through pollen by hermaphrodites enhances nuclear fitness). Recent studies of Silene acaulis and Silene vulgaris have shown that inheritance of the mitochondrial genome is not strictly maternal (Städler and Delph, 2002; McCauley et al., 2005). The evidence is largely indirect and is on the basis of observations suggesting intra- and intergenic recombination within the mitochondrial genome that is detectable when the recombining sequences differ, thus implying mitochondrial heteroplasmy through bi-parental inheritance, which has recently been documented in $S$. vulgaris (Welch et al., 2006). However, the considerable (though imperfect) linkage disequilibrium between mitochondrial genes (McCauley and Ellis, 2008) and a nearly perfect statistical association between mitochondrial and chloroplast genes (Storchova and Olson, 2004) suggests that such 'paternal leakage' is rare.

Another interesting property of Silene mitochondrial genomes is the high level of DNA sequence diversity in the coding regions of some species (Städler and Delph, 2002; Barr et al., 2007), and the high interspecific divergence of mitochondrial gene sequences of others 
(Sloan et al., 2008b). These results contrast with the observation that coding regions of most plant mitochondrial genes are highly conserved. Differences in standing levels of variation and apparent differences in mutation rates between mitochondrial genes may be caused by rare mitochondrial recombination (Barr et al., 2007), but the high level of intra-specific variation sometimes observed is probably a consequence of long-term balancing selection inherent to persistence of CMS genotypes in gynodioecious systems (Städler and Delph, 2002). In S. vulgaris, however, there is suggestive evidence from chloroplast variation for frequent turnover of lineages owing to recurrent selective sweeps in the organellar genomes (Ingvarsson and Taylor, 2002). Theory shows that each of these contrasting outcomes is possible.

Silene chloroplast genes (cpDNA) have been used extensively as markers of seed movement at the metapopulation and phylogeographical levels. Given the potential importance of colonization events for determining the local genetic structure of plant metapopulations with local patchy distribution and frequent turnover, genetic markers that reflect seed movement (such as variable regions of cpDNA, assuming maternal inheritance) are particularly useful and can be compared with nuclear genetic markers for making inferences on the rates of gene flow through pollen and seeds (McCauley, 1994).

\section{Biological invasions}

Beyond the study of mating systems, sex determination, their mechanisms and their consequences, the genus Silene has been instrumental as a biological model for other biological and ecological phenomena, such as biological invasions and trophic interactions. Biological invasions are increasingly being viewed as a major contributor to the loss of biodiversity around the globe, and Silene species are emerging as an outstanding system for research into this phenomenon. S. latifolia and $S$. vulgaris are native to Eurasia, but both are now widespread in parts of North America. The genetic diversity in the species' native and introduced ranges must be determined by both the mode of invasion (a single versus multiple introductions from one or multiple origins), together with the genetic structure in the native range.
Analysis of cpDNA sequences indeed suggests that the differing phylogeographical histories of the two species in Europe affected their respective genetic structures in North America: in S. latifolia, few, discrete invasion events from strongly genetically structured populations in the native range resulted in genetic bottlenecks followed by admixture, whereas invasion in S. vulgaris involved more representative sampling of diversity, with little detectable admixture (Taylor and Keller, 2007).

A major question in biology is why invasive species that are relatively benign competitors in their native ecosystem become dominant after introduction. One explanation is that natural selection in the absence of enemies shifts the optimal investment of resources from defence to enhanced growth and reproduction. S. latifolia was introduced to North America approximately 200 years ago, and there are large differences in the species' biology between the two continents: (1) S. latifolia has escaped some specialist enemies during colonization, and damage levels are higher in Europe (Wolfe, 2002); (2) North American plants are 'weedier' and more reproductively prolific (Blair and Wolfe, 2004), and they invest less in defence and have lower resistance to fungal infection and fruit predation (Wolfe et al., 2004). The development of genomic tools for Silene will soon allow dissection of the genetic changes associated with successful invasions.

\section{Biotic interactions: Microbotryum and the evolutionary ecology of disease}

Another important field of ecology in which Silene is an important model is disease evolution. Many members of the genus Silene are attacked by anther-smut disease caused by the fungus Microbotryum (Figure 5a). This fungus invades the plant and produces spores in the anthers, which replace the normal pollen. The disease sterilizes its host and is transmitted when insects carry spores from infected to healthy flowers during pollination (Antonovics, 2005). In females of dioecious host species, anther development is induced by the pathogen, and this remarkable symptom caught the attention of early researchers including Darwin (1863) to be followed by a series of studies using the pathogen to understand the host's sexual development (for example, Strasburger,
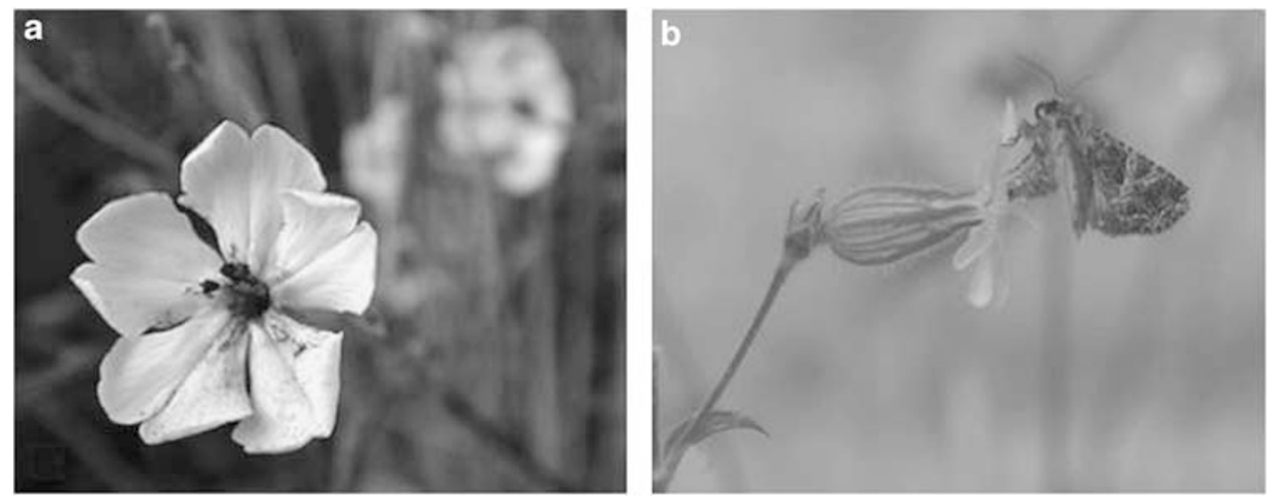

Figure 5 Natural enemies of Silene: (a) The anther-smut fungus infecting a flower of S. paradoxa (ME Hood). (b) Hadena bicruris female ovipositing in a S. latifolia flower (A-M Labouche). 
1900; Shull, 1910). Thus, utility of this disease for studying Silene continues to be shown and is enhanced by modern molecular approaches to gene expression during infection (Uchida et al., 2003; Kazama et al., 2005). Moreover, the smut diseases provide some of the strongest arguments for the value of 'model systems' in their own right. As early as 1755, Mathieu Tillet showed experimentally that grain smut of wheat was transmitted by spores produced in the infected kernels. Had the full implications of this work been realized by the broader scientific world, thousands of lives might have been saved by a much earlier acceptance of the germ theory of disease.

The Silene-Microbotryum system has become a model for studying the evolution of sexually transmitted diseases (Nunn et al., 2000), as well as for studying the forces responsible for host shifts (Antonovics et al., 2002), and the importance of genetic variation in the regional epidemiology of the disease (Antonovics et al., 1997). Ecologists have often ignored the impact of sterilizing and sexually transmitted diseases on the size and distribution of individuals in natural populations, and interesting parallels can be drawn between anther-smut disease and the impact of AIDS on human populations (Figure 6). Anthersmut disease has many advantages for the study of the epidemiology and evolutionary genetics of disease. It has almost no direct agricultural or economic impact, and can therefore readily be studied in many species in natural populations, and experimental populations are easily established in the field (Antonovics et al., 2002). It has a yeast-like stage with two mating types, is easily grown in the lab and has a small genome (ca. $25 \mathrm{Mb}$ ) with chromosomes readily separable by pulse-field gel electrophoresis. Multilocus pathogen and host phylogenies are providing the basis for comparative studies of disease characteristics, including the ecological and evolutionary determinants of host shifts, disease emergence and the evolution of virulence.

Microbotryum also has heteromorphic chromosomes that carry the mating type locus and are sometimes called sex chromosomes. These are the first heteromorphic chromosomes to be discovered in fungi. As in Silene, dimorphism of these chromosomes has repeatedly evolved independently in the genus, they seem to have a region of suppressed recombination, in which transposable elements have accumulated (Hood et al., 2004). However, fungal mating compatibility acts in the haploid stage, so that diploid individuals are always heterozygous and there is no sexual asymmetry in recombination opportunity or exposure of recessives, such as exist for the sex chromosomes of diploids. Similarities in the evolutionary forces acting on diploid sex chromosomes and haploid mating-type chromosomes are currently under study (Hood et al., 2004). As is often the case in biology, parasites have their own parasites. In the case of Microbotryum, these include many transposable elements in its genome. Comparative study of the coevolution of transposable elements with fungal genomic defences (repeat induced point mutations; Hood et al., 2005) is another exciting future research area.

Several other aspects of Microbotryum ecology and genetics also require joint study with its Silene hosts to benefit understanding of both. Microbotryum has recently been shown to consist of different species, highly specialized onto one or two host plants (Le Gac et al., 2007a). Partial premating isolation among host plants also affects Microbotryum because the pathogen transmission depends on the host plants' habitats and pollinators (van Putten et al., 2007). There has however been little, if any, cospeciation between the plants and the fungi (Refrégier et al., 2008). Premating barriers between both close plant and fungal species are weak, making this system an ideal one to evaluate the importance of host and pathogen hybridization in disease evolution (Le Gac et al., 2007b; Karrenberg and Favre, 2008; Minder and Widmer, 2008; Sloan et al., 2008a).

\section{Biotic interactions: pollination and seed predation}

Pollinators play a role in prezygotic reproductive isolation and genetic structure (Richards, 2000; Teixeira and Bernasconi, 2007), but are also important seed predators in Silene (Jolivet and Bernasconi, 2006; Kephart, 2006). Most species are pollinated by moths or bumblebees and have extensively differentiated floral morphologies and scent profiles (Jurgens et al., 2002;
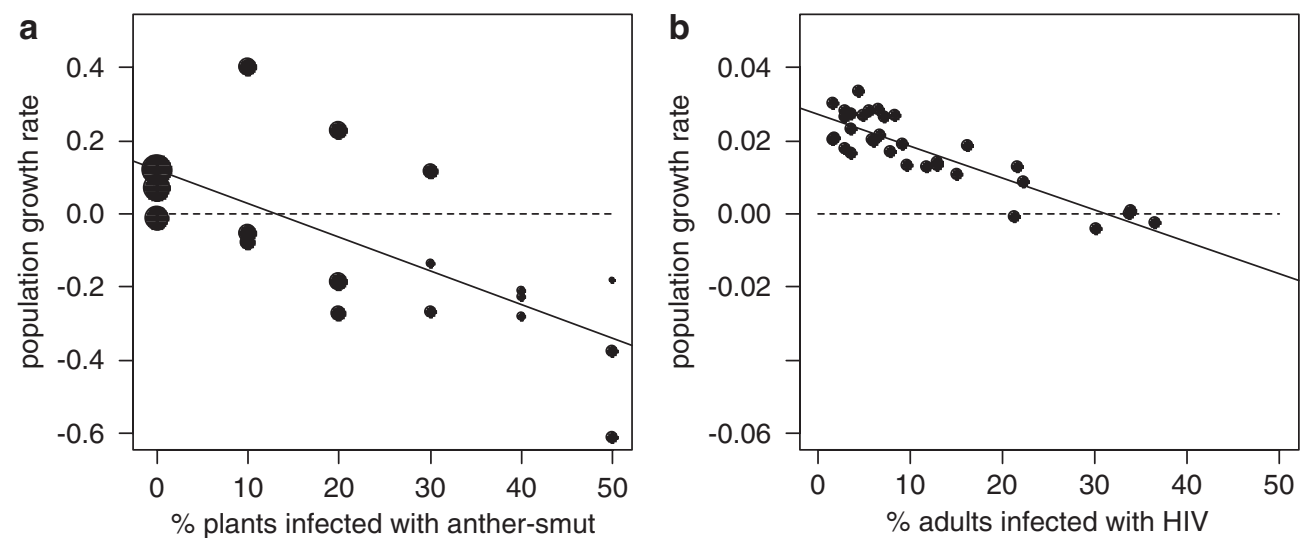

Figure 6 Relationship between population growth and incidence of anther smut in Silene latifolia and HIV in humans. (a) Silene annual growth rates measured as $\ln \left(N_{t+1}+1\right) / N_{t}$ for 1989-1993 in Giles County, Virginia; data grouped by population size (classes 8-15, 16-31, and 32-63), dot sizes are proportional to the number of populations (range =3-239). (b) Data for humans are predicted annual per capita growth rates for 2000-2025 in sub-Saharan African countries; compiled from United Nations, World Population Prospects. The 2002 Revision. Volume III: Analytical Report. 
Jürgens, 2006). Plant-pollinator interactions are generally seen as mutualistic, but antagonism also occurs. Several Silene species are pollinated by nocturnal moths (the lepidopteran fruit predators Hadena, Noctuidae and Perizoma, Geometridae) that lay eggs in the flowers, using the developing seeds as a resource for their progeny (nursery pollination; Figure 5b). But unlike the Yucca/Yucca moth and fig/fig wasp associations (obligate mutualisms), Silene flowers can be pollinated by other insects both in the native (Gimenez-Benavides et al., 2007) and in the introduced ranges (Barthelmess et al., 2006). This offers ideal opportunities for testing how ecological variation in co-pollinator efficiency influences the outcome of the interaction with the seed predator. Silene-Hadena interactions may represent a form of nursery pollination with low or incipient specialization (Kephart, 2006). Recent evidence indicates that fruit abortion (Jolivet and Bernasconi, 2006) and rapid postpollination changes in scent emission (Mühlemann et al., 2006) may regulate seed damage at this early stage of plant-mutualist interaction.

Interactions between herbivores and the pathogens they carry may range from mutualistic to antagonistic. In Silene, nursery pollinators, including Hadena, play a major role in the spread of spores of the anther-smut fungus, affecting pollination and seed set in complex multi-trophic interactions (Carlsson-Graner et al., 1998). Fungal attack reduces the benefits of the interaction to the moth. It is interesting that this is mediated not only by reduced resource quality of infected plants, but also by reduced 'refuge space' for moth larvae (Biere et al., 2002), a factor known to be important in stabilizing trophic interactions in natural communities. Moths respond by avoiding oviposition on infected plants (Biere and Honders, 2006). This system also illustrates that the often complex interactions between organisms at different trophic levels are also affected by human activities. These often lead to fragmentation of S. latifolia habitats in the native range. Reduced population size and increased isolation between plant patches are predicted to differentially affect organisms at different trophic levels. In fragmented native S. latifolia populations, isolation and host population size indeed hardly affect the frequency of Hadena in flowers, but reduce the incidence of some of its parasitoid species (Elzinga et al., 2005).

\section{Conclusions}

The detailed knowledge that has been obtained about Silene and its interacting organisms over more than a century provides a rich source of interesting unresolved questions in plant ecology and evolution. With increasing availability of genetic tools, further progress in Silene should be possible on the range of fundamental questions outlined here. We have highlighted several areas in which new studies are needed; for example, the suppression of recombination during sex chromosome evolution and the role of sexually antagonistic selection in this process. The ecological knowledge available in species of this genus will prove to be an important advantage in comparison with many other systems that were developed as models because of molecular tractability alone, but without information about natural populations. In the age of PCR and genome-wide sequencing of DNA and mRNA, as also illustrated by Mimulus (Wu et al., 2008), molecular non-model species in which interesting biological questions are waiting to be solved attract renewed interest and allow new advances.

\section{Acknowledgements}

We thank the Centro Stefano Franscini (ETH Zurich, Swiss NSF) and the Fondation Herbette of Lausanne University for financial support of the international conference 'Silene: from populations to genes' held at Monte Verità, Ascona, 4-9 May 2008. This work developed at the meeting, and we thank the participants and particularly Jérôme Goudet for the discussion.

\section{References}

Antonovics J (2005). Plant venereal diseases: insights from a messy metaphor. New Phytol 165: 71-80.

Antonovics J, Hood ME, Partain J (2002). The ecology and genetics of a host shift: Microbotryum as a model system. Am Nat 160: S40-S53.

Antonovics J, Thrall PH, Jarosz AM (1997). Genetics and the spatial ecology of species interactions: the Silene-Ustilago system. In: Tilman D, Kareiva P (eds). Spatial Ecology: The Role of Space in Population Dynamics and Interspecific Interactions. Princeton University Press: Princeton, NJ. pp 158-180.

Armstrong SJ, Filatov DA (2008). A cytogenetic view of sex chromosome evolution in plants. Cytogenet Genome Res 120: 241-246.

Baker HG (1963). Evolutionary mechanisms in pollination biology. Science 139: 877-883.

Barr CM, Keller SR, Ingvarsson PK, Sloan DB, Taylor DR (2007). Variation in mutation rate and polymorphism among mitochondrial genes of Silene vulgaris. Mol Biol Evol 24: 1783-1791.

Barrett SCH (2002). The evolution of plant sexual diversity. Nat Rev Genet 3: 274-284.

Barthelmess EL, Richards CM, McCauley DE (2006). Relative effects of nocturnal vs diurnal pollinators and distance on gene flow in small Silene alba populations. New Phytol 169: 689-698.

Bedhomme S, Chippindale A (2007). Irreconcilable differences: when sexual dimorphism fails to resolve sexual conflict. In: Fairbairn DJ, Blanckenhorn WU, Székely T (eds). Sex, Size and Gender Roles. Evolutionary Studies of Sexual Size Dimorphism. Oxford University Press: New York. pp 185-194.

Bergero R, Charlesworth D, Filatov DA, Moore RC (2008). Defining regions and rearrangements of the Silene latifolia $\mathrm{Y}$ chromosome. Genetics 178: 2045-2053.

Bergero R, Forrest A, Kamau E, Charlesworth D (2007). Evolutionary strata on the $\mathrm{X}$ chromosomes of the dioecious plant Silene latifolia: Evidence from new sex-linked genes. Genetics 175: 1945-1954.

Biere A, Elzinga JA, Honders SC, Harvey JA (2002). A plant pathogen reduces the enemy-free space of an insect herbivore on a shared host plant. Proc Royal Soc B 269: 2197-2204.

Biere A, Honders SC (2006). Coping with third parties in a nursery pollination mutualism: Hadena bicruris avoids oviposition on pathogen-infected, less rewarding Silene latifolia. New Phytol 169: 719-727.

Blair AC, Wolfe LM (2004). The evolution of an invasive plant: an experimental study with Silene latifolia. Am Nat 85: 3035-3042.

Carlsson-Graner U, Elmqvist T, Agren J, Gardfjell H, Ingvarsson $P$ (1998). Floral sex ratios, disease and seed set in dioecious Silene dioica. J Ecol 86: 79-91. 
Chase C (2007). Cytoplasmic male sterility: a window to the world of plant mitochondrial-nuclear interactions. Trends Genet 23: 81-90.

Cermak T, Kubat Z, Hobza R, Koblizkova A, Widmer A, Macas $\mathrm{J}$ et al. (2008). Survey of repetitive sequences in Silene latifolia with respect to their distribution on sex chromosomes. Chromosome Res 16: 961-976.

Coyne J, Orr H (1989). Two rules of speciation. In: Otte D, Endler J (eds). Speciation and its Consequences. Sinauer: Sunderland, MA.

Darwin C (1876). The Effects of Cross and Self Fertilisation in the Vegetable Kingdom. J. Murray: London.

Darwin C (1877). The Different Forms of Flowers on Plants of the Same Species. Appleton: New York.

Delph LF (2007). The genetic integration of sexually dimorphic traits in the dioecious plant, Silene latifolia. In: Fairbairn DJ, Blanckenhorn WU, Székely T (eds). Sex, Size and Gender Roles. Evolutionary Studies of Sexual Size Dimorphism. Oxford University Press: New York, p 266.

Delph LF, Mutikainen P (2003). Testing why the sex of the maternal parent affects seedling survival in a gynodioecious species. Evolution 57: 231-239.

Desfeux C, Maurice S, Henry JP, Lejeune B, Gouyon PH (1996). Evolution of reproductive systems in the genus Silene. Proc Royal Soc B 263: 409-414.

Elzinga JA, Turin H, van Damme JMM, Biere A (2005). Plant population size and isolation affect herbivory of Silene latifolia by the specialist herbivore Hadena bicruris and parasitism of the herbivore by parasitoids. Oecologia 144: 416-426.

Filatov DA (2005a). Evolutionary history of Silene latifolia sex chromosomes revealed by genetic mapping of four genes. Genetics 170: 975-979.

Filatov DA (2005b). Isolation of genes from plant Y chromosomes. Meth Enzymol 395: 418-442.

Filatov DA (2005c). Substitution rates in a new Silene latifolia sex-linked gene, SlssX/Y. Mol Biol Evol 22: 402-408.

Filatov DA, Moneger F, Negrutiu I, Charlesworth D (2000). Low variability in a Y-linked plant gene and its implications for Y-chromosome evolution. Nature 404: 388-390.

Geber M, Dawson T, Delph L (eds). (1999). Gender and Sexual Dimorphism in Flowering Plants. Springer: Berlin.

Gimenez-Benavides L, Dötterl S, Jurgens A, Escudero A, Iriondo JM (2007). Generalist diurnal pollination provides greater fitness in a plant with nocturnal pollination syndrome: assessing the effects of a Silene-Hadena interaction. Oikos 116: 1461-1472.

Hood ME, Antonovics J, Koskella B (2004). Shared forces of sex chromosome evolution in haploids and diploids. Genetics 168: 141-146.

Hood ME, Katawczik M, Giraud T (2005). Repeat-induced point mutation and the population structure of transposable elements in Microbotryum violaceum. Genetics 170: 1081-1089.

Ingvarsson P, Taylor D (2002). Genealogical evidence for epidemics of selfish genes. Proc Natl Acad Sci USA 99: 11265-11269.

Ironside JE, Filatov DA (2005). Extreme population structure and high interspecific divergence of the Silene $\mathrm{Y}$ chromosome. Genetics 171: 705-713.

Janousek B, Siroky J, Vyskot B (1996). Epigenetic control of sexual phenotype in a dioecious plant, Melandrium album. Mol Gen Genet 250: 483-490.

Jolivet C, Bernasconi G (2006). Experimental analysis of constitutive and induced defence in a plant-seed-predator system. Funct Ecol 20: 966-972.

Jürgens A (2006). Comparative floral morphometrics in dayflowering, night-flowering and self-pollinated Caryophylloideae (Agrostemma, Dianthus, Saponaria, Silene, and Vaccaria). Plant Syst Evol 257: 233-250.
Jurgens A, Witt T, Gottsberger G (2002). Flower scent composition in night-flowering Silene species (Caryophyllaceae). Biochem Syst Ecol 30: 383-397.

Karrenberg S, Favre A (2008). Genetic and ecological differentiation in the hybridizing campions Silene dioica and $S$ latifolia. Evolution 62: 763-773.

Kazama Y, Koizumi A, Uchida W, Ageez A, Kawano S 2005. Expression of the floral B-function gene SLM2 in female flowers of Silene latifolia infected with the smut fungus Microbotryum violaceum. Plant Cell Physiol 46: 806-811.

Kephart S (2006). Pollination mutualisms in Caryophyllaceae. New Phytol 169: 637-640.

Kubat Z, Hobza R, Vyskot B, Kejnovsky E (2007). Microsatellite accumulation on the plant $\mathrm{Y}$ chromosome in Silene latifolia. Chromosome Res 15: 75-76.

Lahn B, Page D (1999). Four evolutionary strata on the human X chromosome. Science 286: 964-967.

Lardon A, Georgiev S, Aghmir A, Le Merrer G, Negrutiu I (1999). Sexual dimorphism in white campion: complex control of carpel number is revealed by $\mathrm{Y}$ chromosome deletions. Genetics 151: 1173-1185.

Le Gac M, Hood ME, Fournier E, Giraud T (2007a). Phylogenetic evidence of host-specific cryptic species in the anther smut fungus. Evolution 61: 15-26.

Le Gac M, Hood ME, Giraud T (2007b). Evolution of reproductive isolation within a parasitic fungal species complex. Evolution 61: 1781-1787.

Lebel-Hardenack S, Hauser E, Law TF, Schmid J, Grant SR (2002). Mapping of sex determination loci on the white campion (Silene latifolia) Y chromosome using AFLP. Genetics 160: $717-725$

Marais GAB, Nicolas M, Bergero R, Chambrier P, Kejnovsky E, Moneger $\mathrm{F}$ et al. (2008). Evidence for degeneration of the $\mathrm{Y}$ chromosome in the dioecious plant Silene latifolia. Curr Biol 18: $545-549$.

Matsunaga S, Isono E, Kejnovsky E, Vyskot B, Dolezel J, Kawano $S$ et al. (2003). Duplicative transfer of a MADS box gene to a plant $\mathrm{Y}$ chromosome. Mol Biol Evol 20: 1062-1069.

Maurice S, Charlesworth D, Desfeux C, Couvet D, Gouyon PH (1993). The evolution of gender in hermaphrodites of gynodioecious populations with nucleo-cytoplasmic malesterility. Proc R Soc B 251: 253-261.

McCauley D (1994). Contrasting the distribution of chloroplast DNA and allozyme polymorphism among local populations of Silene alba. Proc Natl Acad Sci USA 91: 8127-8131.

McCauley DE, Bailey MF, Sherman NA, Darnell MZ (2005). Evidence for paternal transmission and heteroplasmy in the mitochondrial genome of Silene vulgaris, a gynodioecious plant. Heredity 95: 50-58.

McCauley DE, Ellis JR (2008). Recombination and linkage disequilibrium among mitochondrial genes in structured populations of the gynodioecious plant Silene vulgaris. Evolution 62: 823-832.

Meagher TR (1999). The quantitative genetics of sexual dimorphism. In: Geber M, Dawson T, Delph L (eds). Gender and Sexual Dimorphism in Flowering Plants. Springer: Berlin. pp 275-294.

Minder AM, Widmer A (2008). A population genomic analysis of species boundaries: neutral processes, adaptive divergence and introgression between two hybridizing plant species. Molec Ecol 17: 1552-1563.

Mrackova M, Nicolas M, Hobza R, Negrutiu I, Moneger F, Widmer A et al. (2008). Independent origin of sex chromosomes in two species of the genus Silene. Genetics 179: 1129-1133.

Mühlemann JK, Waelti MO, Widmer A, Schiestl FP (2006). Postpollination changes in floral odor in Silene latifolia: adaptive mechanisms for seed-predator avoidance? J Chem Ecol 32: 1855-1860. 
Negrutiu I, Vyskot B, Barbacar N, Georgiev S, Moneger F (2001). Dioecious plants. a key to the early events of sex chromosome evolution. Plant Physiol 127: 1418-1424.

Nicolas M, Marais G, Hykelova V, Janousek B, Laporte V, Vyskot B et al. (2005). A gradual process of recombination restriction in the evolutionary history of the sex chromosomes in dioecious plants. PLoS Biol 3: E4.

Nunn CL, Gittleman JL, Antonovics J (2000). Promiscuity and the primate immune system. Science 290: 1168-1170.

Oxelman B, Lidén M, Berglund D (1997). Chloroplast rps16 intron phylogeny of the tribe Sileneae (Caryophyllaceae). Plant Syst Evol 206: 393-410.

Refrégier G, Le Gac M, Jabbour F, Widmer A, Hood ME, Yockteng $\mathrm{R}$ et al. (2008). Cophylogeny of the anther smut fungi and their Caryophyllaceous hosts: prevalence of host shifts and Importance of delimiting parasite species. BMC Evol Biol 8: 100.

Renner SS, Ricklefs RE (1995). Dioecy and its correlates in the flowering plants. Am J Bot 82: 596-606.

Richards C (2000). Inbreeding depression and genetic rescue in a plant metapopulation. Am Nat 155: 383-394.

Schultz ST (1994). Nucleo-cytoplasmic male sterility and alternative routes to dioecy. Evolution 48: 1933-1945.

Scotti I, Delph LF (2006). Selective trade-offs and sex-chromosome evolution in Silene latifolia. Evolution 60: 1793-1800.

Shykoff JA (1988). Maintenance of gynodioecy in Silene acaulis (Caryophyllaceae): stage-specific fecundity and viability selection. Am J Bot 75: 844-850.

Shull GH (1910). Inheritance of sex in Lychnis. Bot Gaz 49: 110-125.

Sloan D, Giraud T, Hood ME (2008a). Maximized virulence in a sterilizing pathogen: the anther-smut fungus and its co-evolved hosts. J Evol Biol 21: 1544-1554.

Sloan DB, Barr CM, Olson MS, Keller SR, Taylor DR (2008b). Evolutionary rate variation at multiple levels of biological organization in plant mitochondrial DNA. Mol Biol Evol 25: 243-246.

Städler T, Delph LF (2002). Ancient mitochondrial haplotypes and evidence for intragenic recombination in a gynodioecious plant. Proc Natl Acad Sci USA 99: 11730-11735.

Steven JC, Delph LF, Brodie ED (2007). Sexual dimorphism in the quantitative-genetic architecture of floral, leaf, and allocation traits in Silene latifolia. Evolution 61: 42-57.

Storchova H, Olson MS (2004). Comparison between mitochondrial and chloroplast DNA variation in the native range of Silene vulgaris. Mol Ecol 13: 2909-2919.
Strasburger E (1900). Versuche mit diöcischen Pflanzen in Rücksicht auf Geschlechtsverteilung. Biolog Centralbl 20: 657-665.

Taylor D, Keller S (2007). Historical range expansion determined the phylogenetic diversity introduced during contemporary species invasion. Evolution 61: 334-345.

Teixeira S, Bernasconi G (2007). High prevalence of multiple paternity within fruits in natural populations of Silene latifolia, as revealed by microsatellite DNA analysis. Molec Ecol 16: 4370-4379.

Uchida W, Matsunaga S, Sugiyama R, Kazama Y, Kawano S (2003). Morphological development of anthers induced by the dimorphic smut fungus Microbotryum violaceum in female flowers of the dioecious plant Silene latifolia. Planta 218: $240-248$.

van Putten WF, Elzinga JA, Biere A (2007). Host fidelity of the pollinator guilds of Silene dioica and Silene latifolia: Possible consequences for sympatric host race differentiation of a vectored plant disease. Int J Plant Sci 168: 421-434.

Vyskot B (1999). The role of DNA methylation in plant reproductive development. In: Ainsworth C (ed). Sex Determination in Plants. BIOS Scientific Publishers: Oxford, pp 101-120.

Vyskot B, Araya A, Veuskens J, Negrutiu I, Mouras A (1993). DNA methylation of sex chromosomes in a dioecious plant, Melandrium album. Mol Gen Genet 239: 219-224.

Welch ME, Darnell MZ, McCauley DE (2006). Variable populations within variable populations: quantifying mitochondrial heteroplasmy in natural populations of the gynodioecious plant Silene vulgaris. Genetics 174: 829-837.

Wolfe LM (2002). Why alien invaders succeed: support for the escape-from-enemy hypothesis. Am Nat 160: 705-711.

Wolfe LM, Elzinga JA, Biere A (2004). Increased susceptibility to enemies following introduction in the invasive plant Silene latifolia. Ecol Lett 7: 813-820.

Wu CA, Lowry DB, Cooley AM, Wright KM, Lee YW, Willis JH (2008). Mimulus is an emerging model system for the integration of ecological and genomic studies. Heredity 100: 220-230.

Zluvova J, Janousek B, Negrutiu I, Vyskot B (2005). Comparison of the $\mathrm{X}$ and $\mathrm{Y}$ chromosome organization in Silene latifolia. Genetics 170: 1431-1434

Zluvova J, Georgiev S, Janousek B, Charlesworth D, Vyskot B, Negrutiu L (2007). Early events in the evolution of the Silene latifolia Y chromosome: male specialization and recombination arrest. Genetics 177: 375-386. 